\title{
Effects of Genistein, an Isoflavone, on Pregnancy Outcome and Organ Weights of Pregnant and Lactating Rats and Development of Their Suckling Pups
}

\author{
Yuko TouSEN $^{1}$, Miki UMEKI ${ }^{2}$, Yoko NAKASHIMA ${ }^{1}$, Yoshiko ISHIMI ${ }^{3}$ and Sachie IKEGAMI ${ }^{4}$ \\ ${ }^{1}$ Department of Human Life and Culture, Seitoku University, Matsudo 271-8555, Japan \\ ${ }^{2}$ Faculty of Education and Welfare Science, Oita University, Oita 870-1192, Japan \\ ${ }^{3}$ Division of Applied Food Research, National Institute of Health and Nutrition, Shinjyuku-ku, \\ Tokyo 162-8636, Japan \\ ${ }^{4}$ Department of Home Economics, Otsuma Women's University, Chiyoda-ku, Tokyo 102-8357, Japan
}

(Received June 27, 2005)

\begin{abstract}
Summary There is a general agreement that isoflavones can be beneficial to health in adults. However, isoflavones are well known as endocrine-disrupting chemicals. It should be considered that soy foods might adversely affect the reproductive system and infants. The aim of this study was to evaluate the effects of genistein, an isoflavone, on dams and their offspring. Maternal rats were fed diets containing genistein at levels of 0 and $0.5 \mathrm{~g} / \mathrm{kg}$ diet from pregnancy day 5 to postnatal day 13. No effects of genistein on the delivery, anogenital distance, reproductive organ weight, and body weight of the infants at birth were observed. There were no consistent effects on suckling pups after continuous genistein exposure during their fetal and suckling stages through their mothers, and there was no difference in effects according to the periods of exposure during pregnancy and lactation. We also observed no significant effect on the growth of offspring after weaning. Moreover, while we observed that the serum concentration of triiodothyronine $\left(\mathrm{T}_{3}\right)$ in dams decreased, the result was a tendency, not a significant decrease. Our study suggested that maternal ingestion of genistein might have not induced serious adverse effects on dams, fetuses, infants or offspring during growth. However, the results indicated in many papers suggest the necessity of further study on the safety of genistein.
\end{abstract}

Key Words isoflavone, genistein, pregnant rat, suckling pups

There is general agreement that isoflavones can be beneficial to health in adults as phytoestrogens. Recently, interest in soy ingredients called isoflavones has increased all over the world $(1,2)$. Epidemiological studies suggest that Asian women have a low incidence of breast cancer and estrogen-dependent diseases (3-5). Soybean products are regularly consumed in many East Asian countries, and the soybean is an abundant source of genistein and daidzein. Japanese ingest $1.5 \mathrm{mg} / \mathrm{kg} / \mathrm{d}$ of genistein from the typical Japanese diet, whereas Western people ingest less than $0.2 \mathrm{mg} / \mathrm{kg} / \mathrm{d}$ from their diets (6). The naturally occurring isoflavones, genistein and daidzein, possess estrogenic activity because of their structural similarity. Genistein in particular competes with estradiol through binding to the estrogen receptor and acts as either an estrogen agonist or antagonist because of stronger affinity for the $\beta$-receptor than for the $\alpha$-receptor $(7,8)$. Interest has been generated in isoflavones and their potential use in hormone replacement therapy and osteoporosis prevention $(9,10)$. Furthermore, it is suggested that genistein might prevent some chronic diseases through other mechanisms, including the inhibition of enzymes (aro-

E-mail: tousen@seitoku.ac.jp matase, tyrosine kinase and DNA topoisomerase), increased synthesis of sex hormone-binding globulin, and antioxidation (11-13).

However, there is also concern about isoflavones as endocrine-disrupting chemicals because of their estrogenic activity. Santell et al. reported that phytoestrogens such as genistein produced hypertrophy of the uterus and adverse effects on the reproductive functions in many species (14). Dietary substances that alter hormone levels might affect both the mother and fetus during pregnancy, a hormone-sensitive-period. In contrast, administration of estrogen to pregnant animals has been found to cause detrimental effects on pregnancy. These include decreased weight gain and food intake of pregnant rats, which results in increased fetus resorption or abortion, leading to decreases in the number of live pups, litter size and birth weight (15). Lactation is also a hormone-sensitive and important period in the development of the reproductive capacity of the offspring. Soy products are used as infant formulas in humans. In rats, isoflavones were detected in the milk of dams exposed to isoflavone (16). When infants were given formulas containing soy or milk of dams ingesting the soybean, the effect on their later reproductive functions during puberty should be considered. When early 
infant rats were orally exposed to genistein, the number of females showing estrous cycle irregularities was increased and the fertility in females was disrupted, but not in males. Furthermore, the body weights of the rats were significantly lowered from pubertal to postgrowth (17). Although many papers reported the effects on the infants of exposure to isoflavone in different doses and by different routs (breast milk, oral administration and subcutaneous injection), the results were inconsistent among the papers.

Alternatively, soybean and its products have been also observed to be goitrogenic in humans and animals. It has been reported that soybean feedings in early life have also been associated with the development of autoimmune thyroid disorders (18). However, the reports that observed the effects of isoflavones on the thyroid gland of the dams and their infants are few.

In this experiment, we have chosen the dose level of genistein on the basis of the research previously reported. You et al. reported that the body weight and reproductive function of offspring were suppressed by exposure to genistein through the ingestion of diets at 300 and $800 \mathrm{mg} / \mathrm{kg}$ by pregnant dams (19). However, the exposure of the offspring to genistein had been maintained after weaning in this experiment.

The objective of the present study was to confirm the safety of genistein, an isoflavone, in the dams, fetus, suckling pups and offspring. Therefore, the effect of genistein exposure on the mother in the pregnancy and lactation periods was determined. Experiments to evaluate the following were performed.

1) The effects of genistein feeding at a level $0.5 \mathrm{~g} / \mathrm{kg}$ on pregnancy and the outcome of pregnancy in rat dams.

2) Whether early infant exposure to genistein has any effects on the development before weaning.

3) The long-term reproductive effects and health implications of genistein exposure on offspring during a hormone-dependent development period.

\section{MATERIALS AND METHODS}

Animals. Female Sprague-Dawley (SD) rats at day 5 of gestation were purchased from CLEA Japan, Inc. (Tokyo, Japan). Animals were housed individually in clear plastic cages with a wire-mesh cover and paper chip (ALPHA-DriTM, Shepherd Specialty Papers, Inc., Michigan) bedding. Then weaned offspring were housed individually in stainless-steel cages. Rats were maintained in conditions with a room-controlled temperature $\left(23 \pm 1^{\circ} \mathrm{C}\right)$ and humidity $(50 \pm 5 \%)$, and a $12 \mathrm{~h}$ light : dark cycle. The rats were weighed and randomly allocated to experimental groups. The rats had free access to distilled water, and the food intake of rats was adjusted to the mean food intake of the control group. All rats were maintained according to the guidelines of Law No. 105 and Notification No. 6 of the Japanese government.

Diet and chemicals. Pregnant rats were fed diet mixtures containing genistein at dose levels of 0 and $0.5 \mathrm{~g} /$ $\mathrm{kg}$. These diets were prepared in our facilities based on
Table 1. Composition of experimental diets. ${ }^{1}$

\begin{tabular}{|c|c|c|}
\hline Constituent & \multicolumn{2}{|c|}{$\begin{array}{c}\text { Control diet Genistein diet } \\
\text { ( } \mathrm{g} / \mathrm{kg} \text { diet })\end{array}$} \\
\hline Cornstarch & 529.5 & 529.0 \\
\hline Sucrose & 100 & 100 \\
\hline Casein & 200 & 200 \\
\hline Corn oil & 70 & 70 \\
\hline Cellulose & 50 & 50 \\
\hline Mineral mix & 35 & 35 \\
\hline Vitamin mix & 10 & 10 \\
\hline L-Cystine & 3 & 3 \\
\hline Cholin bitartrate & 2.5 & 2.5 \\
\hline Tert-butyl-hydriquinone & 0.014 & 0.014 \\
\hline Genistein $^{2}$ & 0 & 0.53 \\
\hline
\end{tabular}

${ }^{1}$ Prepared according to AIN-93G formulation.

${ }^{2}$ Genistein (Fujicco Co., Ltd., Kobe, Japan).

the modified AIN-93G diet, except for the replacement of soy oil with corn oil (20). The composition of the diet is shown in Table 1. All ingredients were purchased from Oriental Yeast Co., Ltd. (Tokyo, Japan). The purified genistein used in the experiment (Fujicco Co., Ltd., Kobe, Japan) was $94.85 \%$ as assessed by comparing it to genistein standards using the HPLC analytical method (21).

Experimental design.

Experiment 1: Experiment 1 was performed to clarify the effect of genistein exposure on dams during pregnancy and/or lactation. Pregnant rats $(n=16)$ of random body weight were divided into four groups of 4 rats each: the group fed the control diet, the group exposed to genistein $(0.5 \mathrm{~g}$ genistein $/ \mathrm{kg}$ diet $)$ during both pregnancy and lactation (PL-G), the group exposed to genistein only during pregnancy (P-G), and the group exposed to genistein only during lactation (L-G). After the dams were fed the respective diet in all groups until postnatal day (PND) 13, the genistein diet was changed to the control diet. The progression of pregnancy was observed by measuring daily maternal weight gain and food intake throughout pregnancy. The day of birth was designated as PND 1. On PND 1, number of pups was adjusted to 12 for each dam, and litters were culled to 6 males and 6 females per litter. Pregnancy outcomes were measured in terms of litter size, birth weight and sex ratio. During the lactation period, the weight gain and food intake of pups and dams were measured daily (by litter). Pups on PND 5, 15, and 22 (2 females and 2 males per litter) and dams on PND 22, at weaning, were anesthetized by exposure to diethyl ether. After laparotomy, whole blood was collected by cardiac puncture, and organs were dissected, weighed and stored at $-40^{\circ} \mathrm{C}$.

Experiment 2: Experiment 2 was performed to clarify the effects of genistein exposure of pregnant and nursing dams on their offspring in the growing period. Pregnant rats $(n=12)$ were assigned to two groups of 6 rats each. There were a control diet group and a group of rats exposed to genistein $(0.5 \mathrm{~g}$ genistein $/ \mathrm{kg}$ diet $)$ dur- 
ing pregnancy and lactation (PL-G). Treatment until weaning was done as in experiment 1 . The dams were fed the genistein diet from the pregnancy until PND 13 before the weaning of the pups. At PND 13 the diet was changed from the genistein diet to the control diet so that pups would be exposed to genistein only through the placenta and the milk from the dams. Upon being weaned (PND 22), offspring were housed individually. From PND 22 to PND 75, offspring were weighed weekly. Offspring on PND 5, 15, 22, 49 and 75 (2 females and 2 males per litter) and dams on PND 22 were sacrificed as in experiment 1.

Pup development. Hormonal imbalance in male or female pups due to diet treatment was determined by comparing their measurements of the anogenital distance (AGD) with those of rats receiving the control diet. AGD, the length of the perineum from the base of the genital tubercle to the proximal edge of the anus under the natural extension without stretching, was measured at PND 5, 15 and 22.

Thyroid hormone concentration in the serum of the dam. The measurement of serum thyroid hormones, $\mathrm{T}_{3}$ (triiodothyronine) and $\mathrm{T}_{4}$ (thyroxine) of dams was done by a testing center (SRL Co., Ltd., Japan).

Statistical analyses. Differences were considered to be significant at $p<0.05$. Data were expressed as the means and SD. In experiment 1 , one-way ANOVA was used to determine the differences due to the diet treatment. When ANOVA indicated statistical significance, Duncan's multiple-range test was used to determine which means were significantly different. In experiment 2 , regression analysis was used to examine the relationship between the litter weight and litter size, and AGD and pup weight, respectively. If both intercepts of regression lines were estimated as zero, the litter weight/litter size and AGD/pup weight were calculated and comparisons between the study groups were made by one-way ANOVA. When the intercept was not zero, the mean slopes were compared by analysis of covari- ance with litter size and pup weight as a covariate respectively. In experiment 2 , time-dependent changes in the individual body weight of male and female offspring were analyzed by repeated measures analysis of variance adjusted with degrees of freedom, following Huynh and Feldt (1976). Significance was assigned at $p<0.05$. All statistical tests were performed using a PCbased version of the Statistical Program for the Social Sciences (SPSS) Version 11.0.

\section{RESULTS}

\section{Experiment 1}

Pregnancy outcomes. Compared with the control, ingestion of genistein in the diet throughout pregnancy produced no significant differences in pregnancy outcomes such as litter size, live birth index, or ratio of female vs. male pups (Table 2). The body weights of dams were not affected by exposure to genistein and remarkable effects on pregnancy and delivery from exposure to genistein in dams were not observed.

Body weight and organ weight of pups. Body weights of the male and female pups were not altered by exposure to genistein during the periods of pregnancy and/ or lactation when compared with the results from the control group (Table 3). The liver weight of P-G and LG, kidney weights of PL-G and L-G and spleen weight of P-G were obviously decreased on PND 5 in males, compared with the respective results from the control group. In females, the kidney weight of L-G was decreased with significance compared to that of the control group on PND 5 as illustrated in Table 3. On PND 15, the liver weight of P-G was significantly increased in males (Table 4). On PND 22 (Table 5), the kidney weight of L-G was significantly decreased in males. In females, the liver weights of PL-G and P-G, and the spleen weight of P-G were obviously decreased compared with that in the control group. However, no consistent influence was apparent in any pup during the administration period from PND 1 through 13

Table 2. Body weights of dams fed the control diet or the diet containing $0.5 \mathrm{~g}$ genistein $/ \mathrm{kg}$ during pregnancy and/or lactation, and the number and sex ratio of pups in experiment $1 .{ }^{1}$

\begin{tabular}{|c|c|c|c|c|}
\hline Group $^{2}$ & $\mathrm{C}$ & PL-G & $\mathrm{P}-\mathrm{G}$ & L-G \\
\hline \multicolumn{5}{|l|}{ Dams } \\
\hline$n$ & 4 & 4 & 4 & 4 \\
\hline Body weight (g) & $386.9 \pm 26.2$ & $383.7 \pm 4.2$ & $386.4 \pm 13.5$ & $378.9 \pm 34.8$ \\
\hline \multicolumn{5}{|l|}{ Pups } \\
\hline Total number & $15.5 \pm 2.4$ & $14.8 \pm 1.0$ & $14.8 \pm 3.4$ & $15.0 \pm 1.4$ \\
\hline Male number & $7.5 \pm 1.7$ & $7.8 \pm 0.5$ & $7.3 \pm 4.3$ & $7.8 \pm 1.5$ \\
\hline Female number & $8.0 \pm 2.0$ & $7.0 \pm 0.8$ & $7.5 \pm 1.7$ & $7.3 \pm 1.3$ \\
\hline Litter weight (g) & $95.9 \pm 11.9$ & $95.1 \pm 9.1$ & $92.8 \pm 15.2$ & $91.5 \pm 10.0$ \\
\hline Weight/number (g) & $6.2 \pm 0.2$ & $6.4 \pm 0.3$ & $6.4 \pm 0.5$ & $6.1 \pm 0.2$ \\
\hline Sex ratio of pups ${ }^{3}$ & $0.48 \pm 0.11$ & $0.53 \pm 0.03$ & $0.49 \pm 0.20$ & $0.52 \pm 0.08$ \\
\hline
\end{tabular}


Table 3. Body and organ weights and the anogenital distance of suckling pups of dams fed the control diet or the diet containing $0.5 \mathrm{~g}$ genistein $/ \mathrm{kg}$ during pregnancy and/or lactation in experiment 1 on $\mathrm{PND}^{1} 5 .^{2}$

\begin{tabular}{lcccc}
\hline \multicolumn{1}{c}{ Group $^{3}$} & C & PL-G & P-G & L-G \\
\hline Male & & & & $4(8)$ \\
Litter numbers (pup numbers) & $4(8)$ & $4(8)$ & $4(8)$ & $12.86 \pm 0.98$ \\
Body weight (g) & $11.63 \pm 1.50$ & $12.19 \pm 0.66$ & $11.89 \pm 0.77$ & $5.20 \pm 1.20$ \\
Anogenital distance (mm) & $5.37 \pm 1.42$ & $5.31 \pm 0.77$ & $6.13 \pm 0.64$ & $3.12 \pm 0.26^{\mathrm{b}}$ \\
Liver weight (g/100 g) & $3.54 \pm 0.11^{\mathrm{a}}$ & $3.36 \pm 0.21^{\mathrm{ab}}$ & $3.19 \pm 0.29^{\mathrm{b}}$ & $1.07 \pm 0.08^{\mathrm{b}}$ \\
Kidney weight (g/100 g) & $1.14 \pm 0.06^{\mathrm{a}}$ & $1.06 \pm 0.06^{\mathrm{b}}$ & $1.15 \pm 0.06^{\mathrm{a}}$ & $0.43 \pm 0.07^{\mathrm{ab}}$ \\
Spleen weight (g/100 g) & $0.51 \pm 0.08^{\mathrm{a}}$ & $0.47 \pm 0.03^{\mathrm{ab}}$ & $0.40 \pm 0.04^{\mathrm{b}}$ & $0.18 \pm 0.02$ \\
Thymus weight (g/100 g) & $0.16 \pm 0.03$ & $0.17 \pm 0.03$ & $0.17 \pm 0.04$ & $4(8)$ \\
Female & & & & $11.80 \pm 1.17$ \\
Litter numbers (pup numbers) & $4(8)$ & $4(8)$ & $11.05 \pm 1.50$ & $3.14 \pm 0.46$ \\
Body weight (g) & $11.41 \pm 1.02$ & $12.30 \pm 0.63$ & $3.26 \pm 0.47$ & $3.32 \pm 0.24$ \\
Anogenital distance (mm) & $3.03 \pm 0.72$ & $3.19 \pm 0.43$ & $3.49 \pm 0.25$ & $1.08 \pm 0.07^{\mathrm{b}}$ \\
Liver weight (g/100 g) & $3.64 \pm 0.32$ & $3.37 \pm 0.21$ & $1.21 \pm 0.09^{\mathrm{a}}$ & $0.43 \pm 0.08$ \\
Kidney weight (g/100 g) & $1.16 \pm 0.06^{\mathrm{a}}$ & $1.15 \pm 0.05^{\mathrm{a}}$ & $0.40 \pm 0.08$ & $0.20 \pm 0.04$ \\
Spleen weight (g/100 g) & $0.42 \pm 0.07$ & $0.44 \pm 0.07$ & $0.17 \pm 0.03$ & \\
Thymus weight (g/100 g) & $0.18 \pm 0.04$ & $0.18 \pm 0.03$ & & \\
\hline
\end{tabular}

${ }^{1}$ PND, the day of birth was designated as PND (postnatal day) 1.

${ }^{2}$ All values are means \pm SD. Differences among groups were analyzed by ANOVA and Duncan's multiple-range test. ${ }^{\text {a, b }}$ Values not sharing a superscript letter are significantly different at $p<0.05$.

${ }^{3}$ The group fed the control diet $(\mathrm{C})$, the group exposed to genistein $(0.5 \mathrm{~g}$ genistein $/ \mathrm{kg}$ diet $)$ during both pregnancy and lactation (PL-G), the group exposed to genistein only during pregnancy (P-G), and the group exposed to genistein only during lactation (L-G).

${ }^{4}$ Relative organ weights were calculated as weight/body weight $\times 100$.

Table 4. Body and organ weights and the anogenital distance of suckling pups of dams fed the control diet or the diet containing $0.5 \mathrm{~g}$ genistein $/ \mathrm{kg}$ during pregnancy and/or lactation in experiment 1 on $\mathrm{PND}^{1} 15 .^{2}$

\begin{tabular}{|c|c|c|c|c|}
\hline Group $^{3}$ & $\mathrm{C}$ & PL-G & P-G & L-G \\
\hline \multicolumn{5}{|l|}{ Male } \\
\hline Litter numbers (pup numbers) & $4(8)$ & $4(8)$ & $4(8)$ & $4(8)$ \\
\hline Body weight $(\mathrm{g})$ & $38.5 \pm 4.0$ & $39.4 \pm 0.9$ & $40.1 \pm 1.6$ & $41.9 \pm 3.2$ \\
\hline Anogenital distance (mm) & $7.55 \pm 1.57$ & $8.94 \pm 1.60$ & $8.05 \pm 1.22$ & $9.00 \pm 1.52$ \\
\hline Liver weight $(\mathrm{g} / 100 \mathrm{~g})^{4}$ & $2.74 \pm 0.26^{\mathrm{a}}$ & $2.83 \pm 0.12^{\mathrm{a}}$ & $3.04 \pm 0.13^{\mathrm{b}}$ & $2.92 \pm 0.18^{\mathrm{ab}}$ \\
\hline Kidney weight (g/100 g) & $1.00 \pm 0.08$ & $0.98 \pm 0.04$ & $1.01 \pm 0.05$ & $0.96 \pm 0.04$ \\
\hline Spleen weight (g/100 g) & $0.39 \pm 0.04$ & $0.36 \pm 0.04$ & $0.35 \pm 0.05$ & $0.33 \pm 0.05$ \\
\hline Thymus weight (g/100 g) & $0.31 \pm 0.03$ & $0.31 \pm 0.05$ & $0.34 \pm 0.04$ & $0.33 \pm 0.07$ \\
\hline \multicolumn{5}{|l|}{ Female } \\
\hline Litter numbers (pup numbers) & $4(8)$ & $4(8)$ & $4(8)$ & $4(8)$ \\
\hline Body weight $(\mathrm{g})$ & $37.9 \pm 3.6$ & $37.6 \pm 2.0$ & $38.9 \pm 2.6$ & $40.6 \pm 3.4$ \\
\hline Anogenital distance (mm) & $6.28 \pm 0.94$ & $5.87 \pm 1.03$ & $6.68 \pm 0.60$ & $6.69 \pm 1.12$ \\
\hline Liver weight (g/100 g) & $2.82 \pm 0.24$ & $2.86 \pm 0.24$ & $3.04 \pm 0.16$ & $3.02 \pm 0.16$ \\
\hline Kidney weight (g/100 g) & $1.04 \pm 0.09$ & $1.00 \pm 0.08$ & $1.05 \pm 0.09$ & $0.99 \pm 0.05$ \\
\hline Spleen weight (g/100 g) & $0.38 \pm 0.04$ & $0.35 \pm 0.04$ & $0.36 \pm 0.04$ & $0.34 \pm 0.05$ \\
\hline Thymus weight $(\mathrm{g} / 100 \mathrm{~g})$ & $0.33 \pm 0.03$ & $0.31 \pm 0.03$ & $0.30 \pm 0.04$ & $0.33 \pm 0.07$ \\
\hline
\end{tabular}

${ }^{1}$ PND, the day of birth was designated as PND (postnatal day) 1.

${ }^{2}$ All values are means \pm SD. Differences among groups were analyzed by ANOVA and Duncan’s multiple-range test. ${ }^{\mathrm{a}, \mathrm{b}}$ Values not sharing a superscript letter are significantly different at $p<0.05$.

${ }^{3}$ The group fed the control diet $(\mathrm{C})$, the group exposed to genistein $(0.5 \mathrm{~g}$ genistein $/ \mathrm{kg}$ diet $)$ during both pregnancy and lactation (PL-G), the group exposed to genistein only during pregnancy (P-G), and the group exposed to genistein only during lactation (L-G).

${ }^{4}$ Relative organ weights were calculated as weight/body weight $\times 100$.

(Tables 3, 4 and 5).

Anogenital distance of pups. For the males on PND 15 and PND 22 in the genistein groups of PL-G, P-G and L-G, the tendency that AGD was getting longer was observed in comparison with the control (Tables 4 and 5). There were no consistent effects in reproduction parameters from genistein treatment in the pups (Tables 3, 4 and 5). 
Table 5. Body and organ weights and the anogenital distance of suckling pups of dams fed the control diet or the diet containing $0.5 \mathrm{~g}$ genistein/kg during pregnancy and/or lactation in experiment 1 on $\mathrm{PND}^{1} 22 .^{2}$

\begin{tabular}{|c|c|c|c|c|}
\hline Group $^{3}$ & $\mathrm{C}$ & PL-G & $\mathrm{P}-\mathrm{G}$ & L-G \\
\hline \multicolumn{5}{|l|}{ Male } \\
\hline Litter numbers (pup numbers) & $4(8)$ & $4(8)$ & $4(8)$ & $4(8)$ \\
\hline Body weight $(\mathrm{g})$ & $71.6 \pm 4.6$ & $71.0 \pm 2.6$ & $70.8 \pm 5.7$ & $76.0 \pm 7.4$ \\
\hline Anogenital distance (mm) & $18.11 \pm 2.26$ & $18.64 \pm 1.53$ & $19.68 \pm 1.64$ & $20.04 \pm 1.88$ \\
\hline Liver weight $(\mathrm{g} / 100 \mathrm{~g})^{4}$ & $4.24 \pm 0.24$ & $4.00 \pm 0.25$ & $4.14 \pm 0.29$ & $4.14 \pm 0.11$ \\
\hline Kidney weight (g/100 g) & $0.96 \pm 0.10^{\mathrm{a}}$ & $0.96 \pm 0.04^{\mathrm{a}}$ & $0.99 \pm 0.06^{\mathrm{a}}$ & $0.88 \pm 0.02^{b}$ \\
\hline Spleen weight (g/100 g) & $0.42 \pm 0.07$ & $0.34 \pm 0.06$ & $0.41 \pm 0.09$ & $0.42 \pm 0.03$ \\
\hline Thymus weight (g/100 g) & $0.30 \pm 0.05$ & $0.32 \pm 0.06$ & $0.34 \pm 0.08$ & $0.29 \pm 0.05$ \\
\hline \multicolumn{5}{|l|}{ Female } \\
\hline Litter numbers (pup numbers) & $4(8)$ & $4(8)$ & $4(8)$ & $4(8)$ \\
\hline Body weight (g) & $67.7 \pm 4.3$ & $71.0 \pm 3.2$ & $72.3 \pm 5.0$ & $70.9 \pm 5.7$ \\
\hline Anogenital distance $(\mathrm{mm})$ & $12.37 \pm 1.63$ & $12.48 \pm 1.74$ & $12.90 \pm 1.34$ & $14.11 \pm 1.85$ \\
\hline Liver weight (g/100 g) & $4.25 \pm 0.25^{\mathrm{a}}$ & $3.95 \pm 0.21^{\mathrm{b}}$ & $3.94 \pm 0.18^{\mathrm{b}}$ & $4.21 \pm 0.17^{\mathrm{a}}$ \\
\hline Kidney weight (g/100 g) & $1.06 \pm 0.10$ & $0.99 \pm 0.05$ & $0.98 \pm 0.03$ & $0.97 \pm 0.09$ \\
\hline Spleen weight (g/100 g) & $0.42 \pm 0.05^{\mathrm{a}}$ & $0.39 \pm 0.05^{\mathrm{ab}}$ & $0.35 \pm 0.05^{b}$ & $0.44 \pm 0.05^{\mathrm{a}}$ \\
\hline Thymus weight (g/100 g) & $0.33 \pm 0.04$ & $0.36 \pm 0.08$ & $0.30 \pm 0.05$ & $0.33 \pm 0.06$ \\
\hline
\end{tabular}

${ }^{1}$ PND, the day of birth was designated as PND (postnatal day) 1.

${ }^{2}$ All values are means \pm SD. Differences among groups were analyzed by ANOVA and Duncan's multiple-range test. ${ }^{\mathrm{a}, \mathrm{b}}$ Values not sharing a superscript letter are significantly different at $p<0.05$.

${ }^{3}$ The group fed the control diet $(\mathrm{C})$, the group exposed to genistein $(0.5 \mathrm{~g}$ genistein $/ \mathrm{kg}$ diet $)$ during both pregnancy and lactation (PL-G), the group exposed to genistein only during pregnancy (P-G), and the group exposed to genistein only during lactation (L-G).

${ }^{4}$ Relative organ weights were calculated as weight/body weight $\times 100$.

Table 6. Concentrations of $\mathrm{T}_{3}$ and $\mathrm{T}_{4}$ in the blood of dams fed the control diet or diet containing genistein at $0.5 \mathrm{~g} / \mathrm{kg}$ in experiment $1 .{ }^{1}$

\begin{tabular}{lcccc}
\hline \multicolumn{1}{c}{ Group $^{2}$} & C & PL-G & P-G & L-G \\
\hline Dams & & & & 4 \\
$n$ & 4 & 4 & 4 & $1.18 \pm 0.17$ \\
$\mathrm{~T}_{3}(\mathrm{ng} / \mathrm{mL})$ & $1.32 \pm 0.11$ & $1.14 \pm 0.11$ & $5.84 \pm 0.76$ & $4.76 \pm 0.13$ \\
$\mathrm{~T}_{4}(\mu \mathrm{g} / \mathrm{mL})$ & $5.32 \pm 0.71$ & $4.52 \pm 1.07$ &
\end{tabular}

${ }^{1}$ All values are means \pm SD. Differences among groups were analyzed by ANOVA and Duncan’s multiple-range test $(p<0.05)$.

${ }^{2}$ The group fed the control diet $(\mathrm{C})$, the group exposed to genistein $(0.5 \mathrm{~g}$ genistein $/ \mathrm{kg}$ diet $)$ during both pregnancy and lactation (PL-G), the group exposed to genistein only during pregnancy (P-G), and the group exposed to genistein only during lactation (L-G).

Thyroid hormone concentration in the serum of the dams. Genistein exposure altered circulating thyroid hormone $\mathrm{T}_{3}$ and $\mathrm{T}_{4}$ concentrations as shown in Table 6. In the groups of P-G, L-G and PL-G, which differed in periods of genistein treatment, the tendency of decreased $\mathrm{T}_{3}$ serum concentrations was observed compared with the control group. The genistein groups of PL-G and L-G showed the tendency of decreased $\mathrm{T}_{4}$ serum concentration in dams. It is suggested that genistein exposure during the periods of pregnancy and lactation might influence thyroid hormone concentrations.

Experiment 2

Body weights of offspring. In male and female rats, body weights in the group exposed to genistein during pregnancy and lactation (PL-G) were not markedly different after weaning (Fig. 1).
Reproductive organ weights of offspring. The weights of the uterus and ovaries in the female offspring during development were not altered by genistein exposure for the dams as shown in Table 7 . The weights of the testes and epididymis in the male offspring during their growing period were not different between the PL-G and control groups, either.

\section{DISCUSSION}

In the present study we attempted to determine whether the ingestion of genistein by the dams gave the suckling pups adverse effects. The first objective of the study was to identify the effects of a genistein $0.5 \mathrm{~g} / \mathrm{kg}$ diet on the dam's pregnancy and pregnancy outcomes. Pregnancy and lactation are known to be more hormone-sensitive periods for pups than for the pregnant dams because of the ongoing active sexual differentia- 

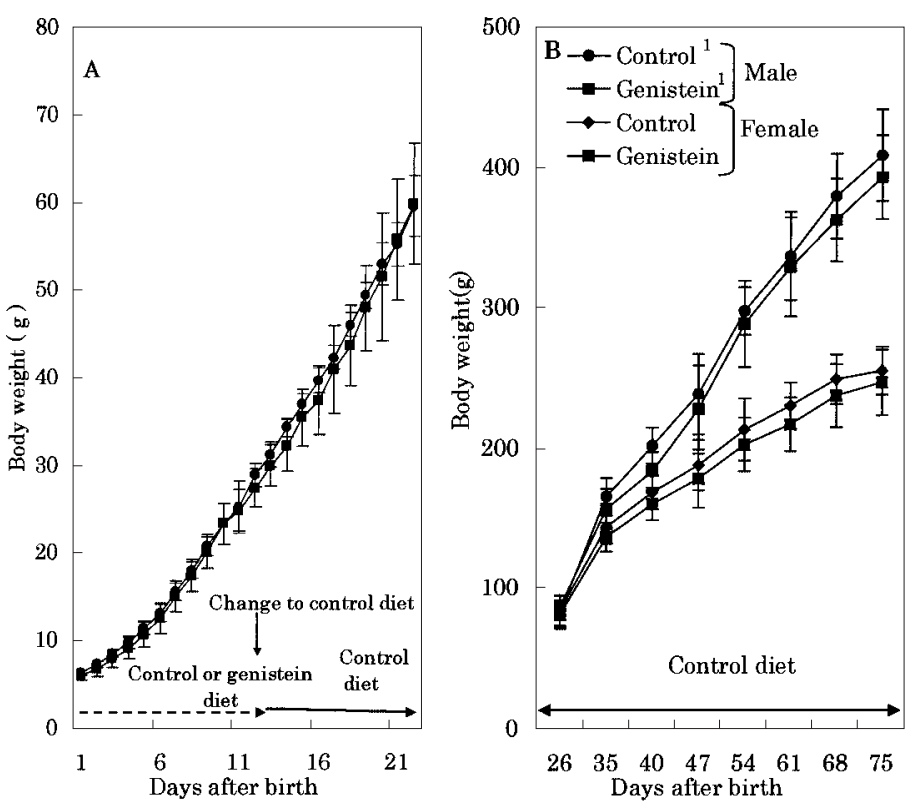

Fig. 1. Changes in the body weights of offspring of dams fed the control diet or diet containing genistein at $0.5 \mathrm{~g} / \mathrm{kg}$ in experiment 2. A: The lactation period from day 1 to day 22 after birth. B: The period after weaning. ${ }^{1}$ Dams of the control diet group were not exposed to genistein and dams of genistein group were exposed to a genistein diet during pregnancy and lactation. In both the male and female, there were no significant effects on the body weights after weaning.

Table 7. Reproductive organ weights of offspring of dams fed the control diet or diet containing genistein at $0.5 \mathrm{~g} / \mathrm{kg}$ in the growing stage in experiment $2 .^{1,2}$

\begin{tabular}{|c|c|c|c|c|}
\hline Group & $\begin{array}{l}\text { Litter numbers } \\
\text { (pup numbers) }\end{array}$ & $\mathrm{PND}^{3} 15$ & PND 49 & PND 75 \\
\hline \multicolumn{5}{|l|}{ Female } \\
\hline \multicolumn{5}{|c|}{ Uterus and ovary weight $(\mathrm{g} / 100 \mathrm{~g})^{4}$} \\
\hline Control & $6(6)$ & $0.10 \pm 0.01$ & $0.23 \pm 0.15$ & $0.20 \pm 0.02$ \\
\hline Genistein & $6(6)$ & $0.13 \pm 0.07$ & $0.24 \pm 0.06$ & $0.18 \pm 0.01$ \\
\hline \multicolumn{5}{|l|}{ Male } \\
\hline \multicolumn{5}{|l|}{ Testis weight $(\mathrm{g} / 100 \mathrm{~g})$} \\
\hline Control & $6(6)$ & $0.29 \pm 0.03$ & $1.02 \pm 0.16$ & $0.84 \pm 0.05$ \\
\hline Genistein & $6(6)$ & $0.28 \pm 0.03$ & $1.06 \pm 0.15$ & $0.90 \pm 0.12$ \\
\hline \multicolumn{5}{|c|}{ Epididymis weight (g/100 g) } \\
\hline Control & $6(6)$ & $0.13 \pm 0.03$ & $0.16 \pm 0.04$ & $0.21 \pm 0.03$ \\
\hline Genistein & $5(5)$ & $0.15 \pm 0.02$ & $0.14 \pm 0.02$ & $0.21 \pm 0.03$ \\
\hline \multicolumn{5}{|c|}{$\begin{array}{l}{ }^{1} \text { All values represent means } \pm \text { SD. Values of the genistein group are not significantly different from the control gro } \\
p<0.05 \text {. }\end{array}$} \\
\hline
\end{tabular}

tion of the pups' reproductive tract. We found no marked alterations in the number of pups produced, ratio of male to female pups, their body weights or AGD by the genistein exposure of the dams (Table 2). Consequently it is suggested that dam exposure to genistein does not have a remarkable influence on the pregnancy or pregnancy outcomes. Kang et al. reported that no estrogenic effects were observed in pregnant rats fed $4.0 \mathrm{mg}$ genistein $/ \mathrm{kg}$ body weight (approximately 1.1$1.4 \mathrm{mg} / \mathrm{d}$ ) when the effects were indicated by the number of live pups, implantation site, sex ratio, AGD, and body weight of live pups (22). In addition, Ryokkynen et al. reported that dietary genistein $(8 \mathrm{mg} / \mathrm{kg}$ body weight/d) administered to pregnant mice resulted in no significant effects on litter size, mortality of pups or sex ratio (23). In contrast, Flynn et al. reported that when pregnant rats were fed a $1,250 \mathrm{mg}$ genistein $/ \mathrm{kg}$ diet, the weight per live pup at birth was decreased (24). In the present experiment, genistein doses calculated from the food intake were $10.1 \mathrm{mg} / \mathrm{d}$ during the pregnancy period and $18.5 \mathrm{mg} / \mathrm{d}$ during $12 \mathrm{~d}$ of lactation. There was a difference between administration methods by 
Kang et al. (orally forced) and us (dietary), and their dose level was one-tenth or less of our level. The dose level by Ryokkynen et al. was five-tenths or less and that by Flynn et al. was 2.5 times as much as our level. The inconsistent results among the studies might be due to the different dose levels and methods.

The second objective of the present study was to evaluate whether early infant exposure to genistein has any effects on the development of pups before weaning. There were no consistent effects on the pups from continuous genistein exposure during pregnancy and lactation and no influence from differences in the period of exposure. AGD as a marker of sexual dimorphism has allowed us to distinguish between the effects of exposure during pregnancy and those during lactation. In our experiment, AGD was not affected by the difference in the genistein exposure during gestation and lactation (Tables 3, 4 and 5).

Lewis et al. reported that when the dams were exposed to genistein during lactation at a level of $50 \mathrm{mg} / \mathrm{kg}$ diet, the concentration in dams' milk was

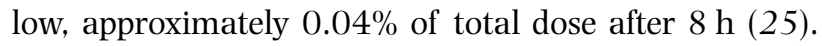
On the other hand, Fritz et al. reported that in the case of the rat dams fed $250 \mathrm{mg}$ genistein $/ \mathrm{kg}$ diet, genistein was detected at high concentrations in the milk of dams and in the stomach contents of suckling pups at PND 7 (137 $\pm 34 \mathrm{pmol} / \mathrm{mL}$ and $4,439 \pm 1,109 \mathrm{pmol} / \mathrm{mL})$, respectively (16). Although the secreted rates of genistein to dams' milk were different among the studies, the proportion of aglycone was high in the each study $(16,25)$. Although in the present experiment, the concentrations of genistein in the serum of nursing dams and dams' milk were not measured, it was confirmed from the previous reports $(16,25)$ that genistein had transfered from the dams to suckling pups, and that the proportion of aglycone was high.

The third objective of the present study was to identify the long-term reproductive effects and health implications of genistein exposure to offspring during a hormone-dependent period. In experiment 2, we observed the effects of early genistein exposure through dams on the offspring in the stage of development. There was no difference in the body weight for the growth period. This evidence suggested that genistein exposure before weaning might not remarkably influence the body weight of offspring for the post-weaning period. It has been shown that dietary genistein $(8 \mathrm{mg} / \mathrm{kg}$ body weight/d) did not affect the body weight of dams or offspring during lactation (23). On the contrary, Flynn et al. reported that when pregnant rats started to be fed $1,250 \mathrm{mg}$ genistein $/ \mathrm{kg}$ diet at gestational day (GD) 7 and the offspring continued on these diets until PND 77 , genistein resulted in decreased maternal food intake and weight gain, and in obviously decreased offspring birth weight and body weight gain from PND 42 to 77 (24). In the same way, Delclos et al. reported that continuous dietary exposure of pregnant rat dams and their offspring to $1,250 \mathrm{mg}$ genistein $/ \mathrm{kg}$ diet from GD 7 to PND 50 resulted in significantly decreased body weights and food intake of dams and offspring (26). As the genistein concentrations in the diet were high in these studies, and the genistein exposure was maintained for the offspring after the weaning, the effect of genistein after weaning is considered to have appeared.

Genistein is well known as an endocrine-disrupting chemical, and it might have adverse effects on the reproductive system $(17,24,26)$. In experiment 2 , we evaluated the hormonal effects of genistein on the reproductive organs in the offspring maternally exposed to genistein during pregnancy and lactation (Table 7). Thereby, the reproductive organ weight of offspring was not affected by the genistein exposure to dams in this experiment. However, Ryokkynen et al. reported that dietary genistein resulted in greater relative prostate and seminal vesicle weights of male pups at PND 21 (23). Although the dose level ( $8 \mathrm{mg} / \mathrm{kg}$ body weight/d) used in their experiment was lower compared with that in our experiment, their result showed the weak adverse effect of genistein on the mouse pups. On the other hand, Delclos et al. reported that dietary exposure of dams during pregnancy and lactation, and the direct genistein exposure of the offspring after weaning were observed to cause the growth suppression, and aberrant or delayed spermatogenesis in male. The results showed that genistein might produce some influences in estrogen-sensitive tissues (26). As we determined only the reproductive organ weight of the offspring to confirm the effects, we should observe the other parameters concerning the long-term effects.

In experiment 2 , dietary genistein decreased concentrations of circulating thyroid hormones, $\mathrm{T}_{3}$ and $\mathrm{T}_{4}$, but not significantly (Table 6). Ryokkynen et al. reported that genistein exposure increased the plasma $\mathrm{T}_{3}$ levels in female pups at PND 21, but no had effects on dams (23). In this experiment, we did not determine the plasma thyroid hormone levels in pups. These results suggest that we need to consider the effects of genistein on the thyroid hormones of dams and pups during the growth period. On the other hand, Chang and Doerge reported that in rats exposed to genistein $(500 \mathrm{mg} / \mathrm{kg}$ diet), the activities of thyroid peroxidase (TPO) were reduced in a dose-dependent manner, but there were no effects on thyroid hormone levels $\left(\mathrm{T}_{3}, \mathrm{~T}_{4}\right.$, and TSH) in serum (27). Suicide inactivation of rat and human TPO was also observed in vitro at concentrations of genistein detected in rat thyroids $(27,28)$. Thus, these results suggested that even though substantial TPO activity was decreased concomitantly with soy isoflavone consumption, the remaining activity was sufficient to maintain thyroid hormone homeostasis.

In the meantime, the average isoflavone intake and genistein intake by Japanese were reported to be 18$54 \mathrm{mg} / \mathrm{d}(29,30)$ and $15-23 \mathrm{mg} / \mathrm{d}(31,32)$. Genistein exposure level in this experiment was almost equal to genistein intake by Japanese from their meals. As there is a difference in the metabolism of genistein between human and rats, the comparison of the intakes based on the body weight might not necessarily be appropriate. However, comparing with the intakes per body weight, the rat dams were administered genistein at 
200 times the usual level of ingestion by Japanese. It would be impossible to consume such a large amount of phytoestrogen from ordinary foods. However, there should be concern about the undesirable effects of isoflavones in unregulated supplementation regimen. There might especially be problems in the transfers to a fetus through the placenta and to an infant through mother's milk.

The exposure to genistein from the diet during pregnancy and lactation did not appear to induce serious influences on the offspring from birth to the post-weaning period. Our experiment suggested that maternal consumption of isoflavones does not have serious adverse effects on dams, fetuses, infants, suckling pups or offspring, but excess feeding might have some effect on the post-growth period. However, the results indicated in many papers suggest the necessity of further study on the safety of genistein.

\section{Acknowledgments}

This study was supported by Health Sciences Research Grants from the Ministry of Health and Welfare, Japan.

\section{REFERENCES}

1) Bingham SA, Atkinson C, Liggins J, Bluck L, Coward A. 1998. Phyto-oestrogens: where are we now? Br J Nutr 79: 393-406.

2) Setchell KD. 1998. Phytoestrogens: the biochemistry, physiology, and implications for human health of soy isoflavones. Am J Clin Nutr 68: 1333S-1346S.

3) Adlercreutz H, Hamalainen E, Gorbach S, Goldin B. 1992. Dietary phyto-oestrogens and the menopause in Japan. Lancet 339: 1233.

4) Magee PJ, Rowland IR. 2004. Phyto-oestrogens, their mechanism of action: current evidence for a role in breast and prostate cancer. Br J Nutr 91: 513-531.

5) Strom SS, Yamamura Y, Duphorne CM, Spitz MR, Babaian RJ, Pillow PC, Hursting SD. 1999. Phytoestrogen intake and prostate cancer: A case-control study using a new database. Nutr Cancer 33: 20-25.

6) Coward L, Barnes NC, Setchell KD, Barnes S. 1993. Genistein and daidzein, and their $\beta$-glycosides conjugates: anti-tumor isoflavones in soybean foods from American and Asian diets. J Agric Food Chem 41: 19611967.

7) Casanova M, You L, Gaido KW, Archibeque-Engle S, Janszen DB, Heck HA. 1999. Developmental effects of dietary phytoestrogens in Sprague-Dawley rats and interactions of genistein and daidzein with rat estrogen receptors $\alpha$ and $\beta$ in vitro. Toxicol Sci 51: 236-244.

8) Kuiper GG, Lemmen JG, Carlsson B, Corton JC, Safe SH, van der Saag PT, van der Burg B, Gustafsson JA. 1998. Interaction of estrogenic chemicals and phytoestrogens with estrogen receptor $\beta$. Endocrinology 139: 42524263.

9) Alekel DL, Germain AS, Peterson CT, Hanson KB, Stewart JW, Toda T. 2000. Isoflavone-rich soy protein isolate attenuates bone loss in the lumbar spine of perimenopausal women. Am J Clin Nutr 72: 844-852.

10) Arjmandi BH, Birnbaum R, Goyal NV, Getlinger MJ, Juma S, Alekel L, Hasler CM, Drum ML, Hollis BW, Kukreja SC. 1998. Bone-sparing effect of soy protein in ovarian hormone-deficient rat is related to its isoflavone content. Am J Clin Nutr 6: 1364S-1368S.

11) Kao YC, Zhou C, Sherman M, Laughton CA, Chen S. 1998. Molecular basis of the inhibition of human aromatase (estrogen synthetase) by flavone and isoflavone phytoestrogens: A site-directed mutagenesis study. Environ Health Perspect 106: 85-92.

12) McCabe MJ, Orrenius S. 1993. Genistein induces apoptosis in immature human thymocytes by inhibiting topoisomerase-II. Biochem Biophys Res Commun 194: 944-950.

13) Fotsis T, Pepper M, Adlercreutz H, Fleischmann G, Hase T, Montesano R, Schweigerer L. 1993. Genistein, a dietary-derived inhibitor of in vitro angiogenesis. Proc Natl Acad Sci USA 90: 2690-2694.

14) Santell RC, Chang YC, Nair MG, Helferich WG. 1997. Dietary genistein exerts estrogenic effects upon the uterus, mammary gland and the hypothalamic/pituitary axis in rats. J Nutr 127: 263-269.

15) Zimmermann SA, Clavenger WR, Brinhall BB, Bradsha WS. 1991. Diethylstilbestrol-induced perinatal lethality in the rat. II. Perturbation of parturition. Biol Reprod 44: $583-589$.

16) Fritz WA, Coward L, Wang J, Lamartiniere CA. 1998. Dietary genistein: perinatal mammary cancer prevention, bioavailability and toxicity testing in rat. Carcinogenesis 19: 2151-2158.

17) Nagao T, Yoshimura S, Saito Y, Nakagomi M, Usumi K, Ono H. 2001. Reproductive effects in male and female rats of neonatal exposure to genistein. Reprod Toxicol 15: 399-411.

18) Fort P, Moses N, Fasano M, Goldberg T, Lifshitz F. 1990. Breast and soy-formula feedings in early infancy and the prevalence of autoimmune thyroid disease in children. J Am Coll Nutr 9: 164-167.

19) You L, Casanova M, Bartolucci EJ, Fryczynski MW, Dorman DC, Everitt JI, Gaido KW, Ross SM, Heck Hd H. 2002. Combined effects of dietary phytoestrogen and synthetic endocrine-active compound on reproductive development in Sprague-Dawley rats: genistein and methoxychlor. Toxicol Sci 66: 91-104.

20) Reeves PG, Nielsen FH, Fahey GC. 1993. AIN-93G purified diets for laboratory rodents: final report of the American Institute of Nutrition ad hoc writing committee on the reformulation of the AIN-76A rodent diet. J Nutr 123: 1939-1951.

21) Gamache PH, Acworth IN. 1998. Analysis of phytoestrogens and polyphenols in plasma, tissue, and urine using HPLC with coulometric array detection. Proc Soc Ex Biol Med 21 7: 274-280.

22) Kang KS, Che JH, Lee YS. 2002. Lack of adverse effects in the F1 offspring maternally exposed to genistein at human intake dose level. Food Chem Toxicol 40: 43-51.

23) Ryokkynen A, Kukkonen JV, Nieminen P. 2006. Effects of dietary genistein on mouse reproduction, postnatal development and weight-regulation. Anim Reprod Sci 93: $337-348$.

24) Flynn KM, Ferguson SA, Delclos KB, Newbold RR. 2000. Effects of genistein exposure on sexually dimorphic behaviors in rats. Toxicol Sci 55: 311-319.

25) Lewis RW, Brooks N, Milburn GM, Soames A, Stone S, Hall M, Ashby J. 2003. The effects of the phytoestrogen genistein on the postnatal development of the rat. Toxicol Sci 71: 74-83.

26) Delclos KB, Bucci TJ, Lomax LG, Latendresse JR, War- 
britton A, Weis CC, Newbold RR. 2001. Effects of dietary genistein exposure during development on male and female CD (Sprague-Dawley) rats. Reprod Toxicol 15: $647-663$.

27) Chang HC, Doerge DR. 2000. Dietary genistein inactivates rat thyroid peroxidase in vivo without an apparent hypothyroid effect. Toxicol Appl Pharmacol 168: 244 252.

28) Doerge DR, Sheehan DM. 2002. Goitrogenic and estrogenic activity of soy isoflavones. Environ Health Perspect 110: 349-353.

29) Somekawa Y, Chiguchi M, Ishibashi T, Aso T. 2001. Soy intake related to menopausal symptoms, serum lipids, and bone mineral density in postmenopausal Japanese women. Obstet Gynecol 97: 109-115.
30) Toda T, Tamura Z, Okuhira T. 1997. Isoflavones content of the marketing soybean foods. FFI Journal 1 72: 83-88 (in Japanese).

31) Wakai K, Egami I, Kato K, Kawamura T, Tamakoshi A, Lin Y, Nakayama T, Wada M, Ohno Y. 1999. Dietary intake and sources of isoflavones among Japanese. Nutr Cancer 33: 139-145.

32) Yamamoto S, Sobue T, Sasaki S, Kobayashi M, Arai Y, Uehara M, Adlercreutz H, Watanabe S, Takahashi T, Iitoi Y, Iwase Y, Akabane M, Tsugane S. 2001. Validity and reproducibility of a self-administered food-frequency questionnaire to assess isoflavone intake in a Japanese population in comparison with dietary records and blood and urine isoflavones. J Nutr 131: 27412747. 